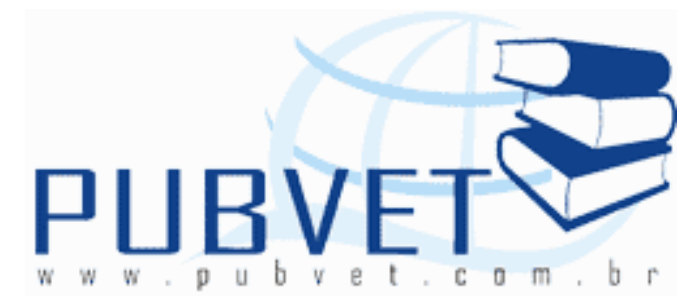

PUBVET, Publicações em Medicina Veterinária e Zootecnia.

\title{
Considerações sobre a utilização da monensina na nutrição de ruminantes
}

\footnotetext{
Francisca Mirlanda Vasconcelos Furtado ${ }^{1}$, Maria Socorro de Souza Carneiro ${ }^{2}$, João Avelar Magalhães ${ }^{3}$, Newton de Lucena Costa ${ }^{4}$, Ítalo Cordeiro Silva Lima ${ }^{5}$, Francisco José de Seixas Santos ${ }^{6}$, Claudio Ramalho Townsend $^{7}$

${ }^{1}$ Zootec., M.Sc., Doutorando em Zootecnia, UFC. Fortaleza, CE.

2 Eng. Agr., D.Sc., Professora do Curso de Doutorado em Zootecnia da UFC. Fortaleza, CE.

${ }^{3}$ Méd.Vet., D.Sc., Pesquisador da Embrapa Meio-Norte. Parnaíba, PI.

${ }^{4}$ Eng. Agr., D.Sc., Pesquisador da Embrapa Roraima. Boa Vista, RR.

${ }^{5}$ Zootec., M.Sc., UFC. Fortaleza, CE.

${ }^{6}$ Eng. Agr., D.Sc., Pesquisador da Embrapa Meio-Norte. Parnaíba, PI

7 Zootec., D.Sc., Pesquisador da Embrapa Rondônia. Porto Velho, RO.
}

\section{Resumo}

A monensina sódica é o ionóforo mais largamente utilizado na nutrição de ruminantes, como forma de aumentar o incremento de proteína de alto valor biológico, através da alteração e manipulação da fermentação ruminal. A utilização da monensina vem sofrendo modificações e proibições em diversos países devido ao risco de intoxicações quando não devidamente utilizada. No 
FURTADO, F.M.V. et al. Considerações sobre a utilização da monensina na nutrição de ruminantes PUBVET, Londrina, V. 6, N. 29, Ed. 216, Art. 1439, 2012.

entanto, quando usada de forma correta, pode melhorar o desempenho produtivo dos animais.

Termos para indexação: intoxicação, ionóforo

\title{
Considerations on the use of monensin in ruminant nutrition
}

\begin{abstract}
The ionophore monensin is the most widely used in ruminant nutrition as a way to increase the increment of protein of high biological value, by modifying and manipulating the rumen fermentation. The use of monensin has undergone changes and bans in several countries due to risk of poisoning when it is not properly used. However, when used correctly, can improve the performance productive of animals.
\end{abstract}

Index terms: intoxication, ionophore

\section{Introdução}

A utilização de aditivos na alimentação animal significa uma forma de incrementar a produção de proteína de alto valor biológico para uma população humana em constante crescimento. É uma medida eficaz para aumentar a produção e rentabilidade das explorações pecuárias. A manipulação e modificação da fermentação ruminal, no sentido de melhorar o desempenho animal, tem sido objetivo de muitas pesquisas em diversas espécies de ruminantes. Dentre os compostos que agem melhorando a qualidade ou a quantidade de nutrientes disponíveis para absorção pelo trato gastrintestinal, e com isso melhorando o desempenho dos ruminantes, destacam-se os ionóforos. A monensina sódica é o ionóforo mais intensivamente utilizado em dietas de ruminantes e, portanto, o mais conhecido, até o momento, quanto aos seus efeitos sobre o padrão de fermentação ruminal e suas conseqüências na produção animal (CAMPOS NETO et al., 1995). 
FURTADO, F.M.V. et al. Considerações sobre a utilização da monensina na nutrição de ruminantes PUBVET, Londrina, V. 6, N. 29, Ed. 216, Art. 1439, 2012.

\section{Monensina}

Existem mais de 70 tipos diferentes de ionóforos, sendo os principais a monensina, lasalocida, salinomicina, narasina, tetronasina, lisocelina e ladilomicina (LANA et al., 2000).

A monensina é um composto biologicamente ativo, produzido por uma cepa de Streptomyces cinnamonensis, pertencendo à classe geral de compostos denominados poliésteres, sendo caracterizada como um ácido monocarboxílico com pKa de 6,65 quando tratada em $66 \%$ de dimetilfosfamida. A sua forma empírica no ácido é $\mathrm{C}_{36} \mathrm{H}_{61} \mathrm{O}_{11} \mathrm{NaH}_{2} \mathrm{O}$ e no sal $\mathrm{C}_{36} \mathrm{H}_{61} \mathrm{O}_{11} \mathrm{Na}$ (ORSINE et al., 1989), sendo utilizada inicialmente nos Estados Unidos no início da década de 1980 como promotor do crescimento e coccidiostático em aves (GELINSKI et al., 2000).

A monensina é um antibiótico carboxílico (SOUZA et al., 2008), conhecido por prevenir a coccidiose em aves e ruminantes inibindo moderadamente 0 crescimento de organismos gram-positivos in vitro (ORSINE et al., 1989), além de diminuir a produção de metano (RÍSPOLI et al., 2009), aumentar as concentrações plasmáticas de glicose (FARIA et al., 2008), melhorando a eficiência do metabolismo energético e proteico, diminuindo a incidência de distúrbios digestivos (RODRIGUES et al., 2001) e melhorando o desempenho produtivo dos animais.

Segundo Nussio et al. (2003) a monensina pode ser usada para controlar a alta mortalidade de bezerros nos primeiros dias de vida, devido à diarréia que tem levado à administração de coccidiostáticos para esses animais em crescimento, visto que, coccidia é um dos agentes causadores de diarréia que pode levar à morte. Alguns dos coccidiostáticos utilizados na criação de bezerras são a lasalocida e monensina.

A monensina vem sendo usada como modelo para examinar os importantes modos de ação na manipulação da função ruminal, tais como: modificação na produção de ácidos graxos, modificação da ingestão alimentar, modificações na produção de gás, modificações na digestibilidade, mudanças 
FURTADO, F.M.V. et al. Considerações sobre a utilização da monensina na nutrição de ruminantes PUBVET, Londrina, V. 6, N. 29, Ed. 216, Art. 1439, 2012.

na utilização de proteína, alterações no enchimento e taxa de passagem no rúmen (SALLES et al., 2001).

\section{Atuação da monensina}

A monensina é capaz de diminuir a produção de ácido lático, contribuindo para a elevação do pH ruminal (LANA et al., 2000), mas consegue manter o pH estável diminuindo a incidência de acidose subclínica em bovinos de leite e corte, devido a inibição das bactérias ruminais produtoras de lactato, enquanto as consumidoras de lactato são resistentes a essa substância (FARIA et al., 2008).

A resistência de bactérias gram-negativas a monensina está relacionada à presença de uma membrana externa, de natureza lipopolissacarídica. A monensina catalisa não apenas trocas de prótons e sódio da membrana plasmática, como também permite trocas de prótons e potássio, enquanto a lasalocida possui maior afinidade por potássio. A ação do ionóforo é mensurada por meio do potássio perdido pela célula (LEOPOLDINO et al., 2007). Segundo Oliveira et al. (2005) as bactérias gram-negativas possuem a habilidade de gerar ATP a partir da fosforilação por transporte de elétrons, originados de grandes reações como do fumarato ao succinato, do crotonil CoA a butiril CoA e do acrililCoA a propionil CoA, e isso faz com que as bactérias gram-negativas sejam resistentes a ação dos ionóforos.

A monensina faz com que a bactéria e outros microorganismos percam a capacidade de expelir prótons e o meio intracelular passa a ser mais ácido que o ambiente externo. Provavelmente, o elevado gasto energético durante a retirada do excesso de $\mathrm{H}^{+}$para tentar manter $\mathrm{o} \mathrm{pH}$ intracelular alcalino iniba o crescimento bacteriano, causando uma sobrecarga de $\mathrm{Ca}^{++}$(ROZZA, 2007).

Quando a monensina liga-se à membrana celular dos microrganismos, ocorrem duas reações. Na primeira reação ocorre a rápida saída de $\mathrm{K}^{+} \mathrm{e}$ entrada de $\mathrm{H}^{+}$na célula, provocada pela mudança do gradiente iônico externo. $\mathrm{O} \mathrm{H}^{+}$acumulado no interior da célula ocasiona diminuição do $\mathrm{pH}$. A célula responde a esta queda no $\mathrm{pH}$ exportando $\mathrm{H}^{+}$para fora e permitindo a entrada 
FURTADO, F.M.V. et al. Considerações sobre a utilização da monensina na nutrição de ruminantes PUBVET, Londrina, V. 6, N. 29, Ed. 216, Art. 1439, 2012.

de $\mathrm{Na}^{+}$para o interior da célula. A segunda reação se caracteriza pelo transporte de $\mathrm{Na}^{+}$para dentro e de $\mathrm{H}^{+}$para fora da célula, embora esta seja menos eficiente que a primeira reação. Outra forma de exportar $\circ \mathrm{H}^{+}$é por meio da bomba de próton ATPase. Assim, grande parte da energia produzida pela célula é utilizada pelas bombas de $\mathrm{Na}^{+} / \mathrm{K}^{+}$e de próton ATPase, na tentativa de manter o pH e o balanço iônico celular. Com o passar do tempo, a célula se torna incapaz de continuar metabolizando a glicose, diminuindo a capacidade de crescimento e reprodução das bactérias, que acabam morrendo ou assumem um nicho microbiano sem expressão ruminal com diminuição da concentração de amônia ruminal, em decorrência da menor degradação de peptídeos e aminoácidos no rúmen, que posteriormente são digeridos e absorvidos no intestino delgado (OLIVEIRA et al., 2005).

Outra ação da monensina é facilitar o transporte iônico através das membranas biológicas por formar complexos lipossolúveis reversíveis com cátions. Esse efeito pode ser seletivamente prejudicial ao tecido muscular devido ao intenso metabolismo de cálcio na miofibra, de forma que a sobrecarga intracelular de $\mathrm{Ca}^{++}$pode exceder a capacidade homeostática e provocar as alterações degenerativas-necróticas na miofibra (ROZZA, 2007).

A monensina quando adicionada nas rações de ruminantes, modifica a fermentação ruminal atuando na proporção molar dos AGV's, promovendo aumento na concentração do ácido propiônico $\left(C_{3}\right)$ em detrimento dos ácidos acético $\left(C_{2}\right)$ e/ ou butírico $\left(C_{4}\right)$, normalmente sem causar alterações que possam vir a prejudicar a produção total dos ácidos graxos voláteis (ORSINE et al., 1989; FARIA et al., 2008). As bactérias gram-positivas, sensíveis ao ionóforo, são produtoras primárias de acetato e butirato, em contrapartida as gram-negativas têm como produto principal de sua fermentação o propionato (SALLES et al., 2001). Já segundo FARIA et al. (2008), a maior produção de propionato promovida pela utilização da monensina poderia estar relacionada à diferença encontrada entre a produção de gases e a degradabilidade da matéria seca (MS). 
FURTADO, F.M.V. et al. Considerações sobre a utilização da monensina na nutrição de ruminantes PUBVET, Londrina, V. 6, N. 29, Ed. 216, Art. 1439, 2012.

Orsine et al. (1989) reportaram que o ácido propiônico é o maior precursor de glicose em ruminantes, contribuindo para reserva de proteína, já que menores quantidades de aminoácidos podem ser desviadas para a gluconeogênese. Os autores sugerem possíveis influências da monensina no metabolismo do nitrogênio, porém a extensão da influência ou da interação com outros nutrientes não tem sido ainda completamente determinada.

A utilização de monensina diminui a ingestão de alimentos, no entanto, Rodrigues et al. (2001) não confirmaram esta hipótese quando os animais são alimentados com dietas predominantemente concentradas. O consumo pode ser incrementado em condições de pastejo, pois a monensina pouco altera o consumo na dieta exclusivamente volumosa. Nussio et al. (2003) relataram que a redução no consumo de MS geralmente observada, seria uma das desvantagens da monensina na dieta de animais em aleitamento, uma vez que poderia atrasar a desmama em sistemas onde se adota o consumo de concentrado como critério para desmama. Araújo et al. (2006) destacaram que o consumo voluntário de alimentos e $\mathrm{opH}$ do líquido ruminal não foram influenciados pela adição da monensina sódica na dieta dos ovinos. Há vários artigos que divergem quanto os benefícios e/ou malefícios que a monensina causam com relação ao consumo voluntário de MS, mas tais trabalhos não informam a idade dos animais e de acordo com Nussio et al. (2003) os ruminantes jovens podem fazer uso diferenciado da monensina, em relação a animais adultos.

O efeito maior da monensina se dá em dietas à base de forrageiras ricas em proteínas, pois, sob estas condições, a taxa de degradação de proteína é maior que a taxa de fermentação de carboidratos e os níveis de amônia ruminal geralmente são altos (LANA et al., 2000). Bactérias ruminais provenientes de animais recebendo dieta exclusiva de forragem são mais sensíveis à monensina que aquelas de animais sob dietas ricas em concentrado, indicando que este ionóforo pode ter maior benefício no desempenho de bovinos em pastagens ou em dietas contendo elevado nível de 
FURTADO, F.M.V. et al. Considerações sobre a utilização da monensina na nutrição de ruminantes PUBVET, Londrina, V. 6, N. 29, Ed. 216, Art. 1439, 2012.

volumoso em comparação àquelas ricas em concentrado (LANA e RUSSELL, 2001).

Vários autores, citados por Rodrigues et al. (2001), destacaram que a monensina diminui a digestibilidade da fibra principalmente em dietas com altas porções de concentrados, mas aumenta a digestibilidade das frações fibrosas em dietas predominantemente volumosas. Algum tempo depois os mesmos autores observaram que a monensina era capaz de aumentar a digestibilidade da fibra e proteína à medida que a proporção de volumoso diminuía. Em outros trabalhos, entretanto, não foram encontrados efeitos dos ionóforos sobre a digestibilidade da MS, fibra, proteína bruta (PB), matéria orgânica, amido em qualquer que fosse o nível de fibra na dieta.

\section{Monensina associada a outros produtos e alimentos}

Ríspoli et al. (2009), em estudo comparando a ação entre própolis e monensina em bovinos de raça holandesa e bubalinos da raça Murrah, em que os animais foram submetidos a dietas com tratamento sem aditivo; dieta e monensina sódica (Rumensin); e dieta e aditivos à base de própolis, constituída de um núcleo para ração e extrato de própolis, perceberam que a inclusão da monensina e dos extratos de própolis mostraram atuar sobre as populações de ciliados no rúmen dos bubalinos da raça Murrah. O gênero Entodinium é o mais representativo tanto em bovinos quanto em bubalinos, mas os bubalinos possuem uma população de ciliados maiores que os bovinos.

Faria et al. (2008) estudaram o uso da adição de monensina isolada e associada com polpa cítrica e propilenoglicol. As formas de utilização não promoveram alterações na velocidade de fermentação dos substratos, pois as taxas de produção de gases foram muito próximas entre os tratamentos, variando entre 0,09 (polpa cítrica, polpa cítrica + monensina e polpa cítrica + propilenoglicol + monensina) e $0,10 \mathrm{ml} / \mathrm{g}$ de carboidratos totais (polpa cítrica + propilenoglicol). No mesmo estudo os autores concluíram que o menor potencial de produção de gases foi devido aos altos níveis de ionóforos na dieta dos ruminantes. Eifert et al. (2005) avaliaram o efeito da adição 
FURTADO, F.M.V. et al. Considerações sobre a utilização da monensina na nutrição de ruminantes PUBVET, Londrina, V. 6, N. 29, Ed. 216, Art. 1439, 2012.

simultânea de ionóforos e gorduras na alimentação de ruminantes, concluindo que a ação no rúmen, parece ser dependente da fonte de gordura e do ionóforo utilizado.

Gelinski et al. (2000) associaram uma fonte de nitrogênio não proteico de degradação lenta, com um poupador de proteólise ruminal (Rumensin), tentando favorecer a hidrólise da celulose, que é degradada por bactérias dependentes de nitrogênio. Os autores observaram que na ração total misturada, a ureia de liberação lenta reduziu o consumo alimentar e prejudicou a performance dos animais. No mesmo estudo não houve efeito da monensina sobre os parâmetros, provavelmente em função do baixo nível de PB da dieta utilizada no experimento, não ocorrendo interação entre os dois componentes testados.

Segundo Salles et al. (2001), a inclusão de monensina na dieta de novilhas afetou sua reprodução, levando ao amadurecimento precoce e em fermentação ruminal a favor do ácido propiônico, melhorando a taxa de crescimento corporal e produzindo resposta endócrina, que aparentemente influi nos mecanismos reguladores da puberdade. Lima et al. (2008) ressaltaram que a monensina sódica melhora a conversão alimentar e o ganho de peso médio diário, podendo levar à precocidade reprodutiva dos animais, pois melhora a eficiência do metabolismo energético e nitrogenado no rúmen.

Os ionóforos proporcionam maior eficiência na utilização da proteína pelos animais ruminantes, quando a dieta apresenta alta relação proteína:carboidrato fermentescível e o $\mathrm{pH}$ ruminal é elevado, como no caso de animais sob alimentação de volumosos de boa qualidade (LANA et al., 2000).

Salles e Lucci (2000) estudaram o efeito da adição de monesina no desempenho de bezerros desaleitados, que seriam descartados em um sistema de produção leiteira. Os animais foram submetidos ao emprego de diferentes níveis de monensina, visando o aumento de peso e a posterior análise da carcaça. Os autores observaram o ganho de peso até os animais atingirem 120 
FURTADO, F.M.V. et al. Considerações sobre a utilização da monensina na nutrição de ruminantes PUBVET, Londrina, V. 6, N. 29, Ed. 216, Art. 1439, 2012.

dias, logo após o abate e verificaram que a carcaça analisada mostrou-se com maior quantidade de carne comercializável com a utilização do ionóforo.

O processamento de grãos beneficia a fermentação ruminal e Nussio et al. (2003) relataram que a floculação do milho, apesar de ser comprovadamente benéfica para bovinos com o rúmen plenamente funcional, não melhora o desempenho de animais mais jovens, na fase pré-desmama, e durante as primeiras semanas pós desmama. Chavira et al. (2010) estudaram os efeitos da suplementação de dietas de confinamento com ionóforos e da raça do animal na taxa de crescimento e nas características de carcaça de cordeiros deslanados e relataram que a taxa de crescimento não foi influenciada pela inclusão de ionóforos na dieta. Cordeiros Pelibuey $\times$ Dorper podem ter maior ganho de peso diário e melhores características de carcaça que cordeiros Pelibuey $\times$ Damara.

\section{Intoxicação por monensina}

A intoxicação acidental por monensina resulta freqüentemente de falhas na preparação das dietas, tais como alta dosagem, erro na diluição da ração, e na identificação de recipientes, uso da substância em espécies não incluídas nas recomendações do produto. A concentração tóxica de monensina é variável e depende da espécie animal, sendo os eqüinos os mais sensíveis. A maior parte dos problemas de intoxicação dá-se no período inicial de adição de ionóforo à dieta e muitas vezes envolvem erros na mistura e superdosagem. Em razão disto, a adoção de novas práticas de manejo têm levado a modificação de hábitos alimentares que podem acarretar no surgimento de distúrbios fermentativos dos pré-estômagos, como a acidose láctica ruminal, doença que tem sido cada vez mais incriminada nos processos patológicos que acometem os ruminantes criados intensivamente (ROZZA, 2007; SOUZA et al., 2008; MIRANDA NETO et al., 2009).

O período entre a ingestão e o aparecimento dos sinais clínicos varia entre 18 horas e quatro dias dependendo, principalmente, da quantidade ingerida. Inicialmente, ocorre anorexia, a seguir diarreia, apatia, tremores, ataxia, 
FURTADO, F.M.V. et al. Considerações sobre a utilização da monensina na nutrição de ruminantes PUBVET, Londrina, V. 6, N. 29, Ed. 216, Art. 1439, 2012.

fraqueza muscular, andar arrastando as pinças, taquicardia, dispnéia, distúrbios locomotores, mioglobinúria, decúbito esternal, parada do rúmen e morte (ROZZA, 2007; FRANÇA et al., 2009).

França et al. (2009), observaram em uma intoxicação acidental em ovinos ocorrido no estado do Rio de Janeiro que a monensina provocou alterações no miocárdio e nos músculos esqueléticos, porém as lesões cardíacas predominaram sobre as da musculatura esquelética. A incoordenação motora observada nessa intoxicação pode ser resultado da interferência do ionóforo na neurotransmissão periférica, não descartando a possibilidade do sintoma ser consequência da incapacitação muscular difusa causada pelas lesões musculares. Quantidades em torno de $60 \mathrm{~g} /$ tonelada em $100 \mathrm{~kg}$ de ração, podem ser a causa da toxicose em ovinos. Em ovinos afetados, as concentrações plasmáticas de creatinina fosfoquinase são elevadas e os sinais clínicos incluem anorexia, diarréia, ataxia, debilidade muscular, perda de peso, recumbência e morte. (SOUZA et al., 2008).

A monensina é rapidamente excretada após sua ingestão, com mínimo acúmulo nos tecidos animais. Entretanto, existe a possibilidade que a taxa de excreção metabólica seja excedida e efeitos tóxicos surjam em animais recebendo dieta com monensina ou em seres humanos consumindo tecidos desses animais. O curso clínico da intoxicação varia conforme a intensidade da dose e o tempo da ingestão (SOUZA et al., 2008). Os ionóforos se distribuem amplamente pelo organismo sendo encontrados em tecidos e líquidos orgânicos, incluindo soro sanguíneo, pulmão, fígado, músculo, gordura, rim, pele e coração (ROZZA, 2007). Os tecidos primariamente afetados são o muscular estriado cardíaco e o esquelético (SOUZA et al., 2008).

Devido à toxidade, o uso de ionóforos, como a monensina na nutrição de animais ruminantes, é considerado um risco crescente para a saúde humana, e os mercados consumidores internacionais têm se mostrado intolerantes aos produtos originados de animais que recebem esse tipo de dieta (MORAIS et al., 2006), sendo proibido sua utilização nos Estados Unidos e outros países (FRANÇA et al., 2009). 
FURTADO, F.M.V. et al. Considerações sobre a utilização da monensina na nutrição de ruminantes PUBVET, Londrina, V. 6, N. 29, Ed. 216, Art. 1439, 2012.

A utilização de monensina sódica é de grande beneficio na alimentação dos ruminantes, desde que seguidas às recomendações necessárias para o uso correto, sem acarretar possíveis intoxicações nos animais.

\section{Considerações finais}

A monensina quando usada de forma correta pode auxiliar o ganho em produtividade animal em consequência do aumento e melhora da síntese proteica.

\section{Referências Bibliográficas}

ARAÚJO, J.S.; PEREZ, J.R.O.; PAIVA, P.C.A.; PEIXOTO, E.C.T.M.; BRAGA, G.C.; OLIVEIRA, V.; VALLE, L.C.D. Efeito da monensina sódica no consumo de alimentos e ph ruminal em ovinos. Archives of Veterinary Science, v. 11, n.1, p.39-43, 2006.

CAMPOS NETO, O.; RAMOS, A.A.; ESCOBAR, M.J.; DALANESI, J.A.; DE BEM, C.H.W. Avaliação da monensina sódica em vacas leiteiras. Scientia Agricola, v.52, n.2, p. 268-273, 1995.

CHAVIRA, J.S.; JUAREZ, A.L.; GONZÁLEZ, A.G.; CASTRO, J.J.; CASTILLO, R.G.; BRIBIESCA, E.R. Efeito do grupo genético e da suplementação com ionóforos sobre o crescimento e as características de carcaça de cordeiros deslanados confinados. Revista Brasileira de Zootecnia, v.39, n.3, p.633-637, 2010.

EIFERT, E.C.; LANA R. P.; LEÃO, M.I.; ARCURI, P.B.; VALADARES FILHO, S.C.; LEOPOLDINO, W.M.; OLIVEIRA, J.S.; SAMPAIO, C.B. Efeito da combinação de óleo de soja e monensina na dieta sobre o consumo de matéria seca e a digestão em vacas lactantes. Revista Brasileira de Zootecnia, v.34, n.1, p.297-308, 2005.

FARIA B.N.; REIS R.B.; MAURÍCIO R.M.; LANA A.M.Q.; LEITE L.A.; COELHO S.G.; SATURNINO H.M. Efeitos da adição de monensina ou propilenoglicol à polpa cítrica sobre a cinética de degradação dos carboidratos totais e da produção cumulativa de gases in vitro. Arquivo Brasileiro de Medicina Veterinária e Zootecnia, v.60, n.3, p.691-697, 2008.

FRANÇA, T.N.; NOGUEIRA, V.A.; YAMASAKI, E.M.; CALDAS, S.A.; TOKARNIA, C.H.; PEIXOTO, P.V. Intoxicação acidental por monensina em ovinos no Estado do Rio de Janeiro. Pesquisa Veterinária Brasileira, v. 29, n.9, p.743-746, 2009.

GELINSKI, L.A.M.; ANDRIGUETTO, J.L.; ROSSI JÚNIOR, P. Monensina e uréia de liberação lenta no desempenho de bovinos confinados. Archives of Veterinary Science, v.5, p.137$140,2000$.

LANA, R.P.; CUNHA, L.T.; BORGES, A.C. Efeito da monensina na fermentação da proteína de algumas fontes de alimentos. Revista Brasileira de Zootecnia, v.29, n.6, p.1868-1875, 2000. 
LANA, R.P.; RUSSEL, J.B. Efeitos da monensina sobre a fermentação e sensibilidade de bactérias ruminais de bovinos sob dietas ricas em volumoso ou concentrado. Revista Brasileira de Zootecnia, v.30, n.1, p.254-260, 2001.

LEOPOLDINO, W.M.; LANA, R.P.; EIFERT, E.C.; ARCURI, P.B.; MANTOVANI, H.C.; MARTINS, R.G.R. Avaliação de ionóforos pela técnica da perda do potássio celular e produção de gases in vitro. Arquivo Brasileiro de Medicina Veterinária e Zootecnia, v.59, n.6, p.1516-1522, 2007.

LIMA, C.S.; GAMBARINI, M.L.; VIU, M.A.O.; FILHO, B.D.O; SANTOS, F.C.; CAIXETA, L.S. Efeito da bioestimulação, monensina e somatotropina recombinante bovina sobre o ganho médio diário e início da puberdade em novilhas girolando criadas a pasto. Archives of Veterinary Science, v.13, n.2, p.93-97, 2008.

MIRANDA NETO, E.G.; AFONSO, J.A.B.; SILVA, S.T.G.; MENDONÇA, C.L. Utilização da monensina sódica na prevenção da acidose láctica ruminal induzida em caprinos (resultados preliminares). Ciência Animal Brasileira - Suplemento 1, Anais do VIII Congresso Brasileiro de Buiatria, p.128-133, 2009.

MORAIS, J.A.S.; BERCHIELLI, T.T.; REIS, R.A. Aditivos. In: BERCHIELLI, T.T.; PIRES, A.V.; OLIVEIRA, S.G. (Eds.). Nutrição de ruminantes. Jaboticabal: Funep, 2006. 583p.

NUSSIO, C.M.B.; SANTOS, F.A.P.; ZOPOLLATTO, M.; PIRES, A.V., MORAIS, J.B. Processamento de milho (floculado vs. laminado a vapor) e adição de monensina para bezerras leiteiras, pré e pós-desmama precoce. Revista Brasileira de Zootecnia, v.32, n.1, p.229-239, 2003.

OLIVEIRA, M.V.M.; LANA, R.P.; JHAM, G.N.; PEREIRA, J.C.; PÉREZ, J.R.O.; VALADARES FILHO, S.C. Influência da monensina no consumo e na fermentação ruminal em bovinos recebendo dietas com teores baixos e altos de proteína. Revista Brasileira de Zootecnia, v.34, n.5, p.1763-1774, 2005.

ORSINE, F.G.; RODRIGUES, N.M.; SOCORRO, E.P. Monensina sódica como aditivo de forragem. II- efeitos no metabolismo ruminal e concentração de glicose e uréia no sangue. Anais da Escola de Agronomia e Veterinária, v.01, n.19, p. 39-48. 1989.

RÍSPOLI, T.B.; RODRIGUES I.L.; MARTINS NETO R.G.; KAZAMA R.; PRADO O.P.P.; ZEOULA L.M.; ARCURI P.B. Protozoários ciliados do rúmen de bovinos e bubalinos alimentados com dietas suplementadas com monensina ou própolis. Pesquisa Agropecuária Brasileira, v.44, n.1, p.92-97, 2009.

RODRIGUES, P.H.M.; MATTOS, W.R.S.; MELOTTI, L.; RODRIGUES, R.R. Monensina e digestibilidade aparente em ovinos alimentados com proporções de volumoso/concentrado. Scientia Agricola, v.58, n.3, p.449-455, 2001.

ROZZA, D.B. Intoxicação por monensina em búfalos. Porto Alegre: Universidade Federal do Rio Grande do Sul, 2007. 49f. (Tese de Doutoado).

SALLES, M.S.V.; LUCCI, C.S. Monensina para bezerros ruminantes em crescimento acelerado. 1. Desempenho. Revista Brasileira de Zootecnia, v.29, n.2, p.573-581, 2000.

SALLES, M.S.V.; ZANETTI, M.A.; CONTI, R.M.C.; LIMA, C.G. Efeitos da monensina no desempenho de bezerras leiteiras em crescimento. Revista Brasileira de Zootecnia, v.30, n.4, p.1293-1298, 2001. 
SOUZA, T.S.; COSTA, J.N.; SILVA, A.E.; MOREIRA, E.L.T.; FERREIRA, M.M.; COSTA, A.F. Intoxicação por monensina em ovinos. Archives of Veterinary Science, v.13, n.4, p.280284, 2008. 